\title{
Are there Alternative Conceptual Frameworks?
}

\author{
STEVEN YATES \\ University of Georgia
}

Richard Rorty and Donald Davidson have offered separate but related arguments against the intelligibility of the notion that there are alternative conceptual frameworks, and of the notion conceptual framework itself.' Rorty concludes his argument with the claim that the "notion of alternative conceptual frameworks - contains the seeds of doubt about the root notion of 'conceptual framework', and so of its own destruction." He bases this conclusion on an earlier argument against the Kantian notion of the faculty of receptivity: the possibility of alternative conceptual frameworks would serve to show that Kantian intuitions and faculties are incapable of determining the content of experience. Consequently, such postulates are of little value as explanatory tools and can safely be eliminated. As Rorty puts it:

There seems no need to postulate an intermediary between the physical thrust of the stimulus upon the organ and the full-fledged conscious judgment that the properly programmed organism forms in consequence. Thus there is no need to split the organism up into a receptive wax tablet on the one hand and an "active" interpreter of what nature has there imprinted on the other.'

For Davidson, whom Rorty follows closely on this point, the notion of a conceptual framework is merely one half of a distinction between conceptual scheme (as Davidson calls it, following Quine) and empirical content; his chief claim is that this distinction, this

dualism of scheme and content, of organizing system and something waiting to be organized, cannot be made intelligible and defensible. It is itself a dogma of empiricism, the third dogma. The third, and perhaps the last, for if we give it up it is not clear that there is anything left to call empiricism."

In this paper it shall be my aim to spell out and defend a version of the doctrine of conceptual frame- 
works and alternative conceptual frameworks which escapes Rorty's and Davidson's criticisms. I will also attempt to show that Rorty's position at least requires the version of conceptual frameworks I wish to introduce and discuss. Rorty, following earlier pragmatists," rebels against the Cartesian and Kantian vocabularies and priorities; Davidson also resists drawing the kinds of distinctions Cartesians and Kantians and their followers have drawn. I will simply assume that these moves are correct; in particular, I will assume that any version of the idea of a conceptual scheme which requires distinctions between mind and body as two separate kinds of "stuff," between the Kantian a priori and a posteriori as setting eternal preconditions of knowing, and between analytic and synthetic as permanent categories of propositions, has been shown to be untenable, must be given up, and good riddance. In proceeding I will argue that none of these traditional categories are necessary for an intelligible notion of alternative conceptual frameworks, and that scientific findings can be used in support of the idea of the conceptual scheme I want to defend.

My argument begins with incommensurability, a notion Rorty has endorsed. The incommensurability thesis is among the most controversial of all the notions introduced by recent "historicist" philosophers of science. Without using the term incommensurability, N.R. Hanson argued effectively against the standard observational-theoretical distinction:

There is a sense in which seeing is a theoryladen undertaking. Observation of $x$ is shaped by prior knowledge of $x$. Another influence on observations rests in the language or notation used to express what we know, and without which there would be little we could recognize as knowledge."

This opened the way for Kuhn's better known discussions of "Incommensurable ways of seeing the world and of practicing science in it" as due to change of meaning and reference of crucial terms from one theory to its successor or competitor.' Equivalent remarks can be found in Toulmin's and, of course, Feyerabend's writings from this period." All these views, and especially the claim that incommensurable theories can act as genuine competitiors, have undergone detailed and oftentimes severe criticism, but the incommensurability thesis seems to have survived all attempts at refutation." As Kuhn recently wrote, "virtually no one has fully faced the difficulties that led Feyerabend and me to speak of incommensurability."10 These difficulties arise out of the historical evidence that at crucial junctures fundamentally new sets of interrelated concepts have been introduced. Newton, for instance, in his Principia introduced concepts of mass, force, 
space, time, etc., which had only the most indirect counterparts in the Aristotelian tradition which used notions like natural versus violent motion, and terrestrial versus celestial substance, regarded space as both finite and having a privileged center, and so on. Likewise, the anthropological linguist B. L. Whorf, writing earlier than any of the historicists in philosophy of science, concluded from close study of the Hopi language that Hopi cosmology--his term was Hopi metaphysics--had no exact equivalent to the Western conception of time. 11

Davidson, among many others, 12 has contended that conceptual contrasts of the kind just outlined make the pairs involved incomparable, arguing from incomparability to conceptual relativism. And this doctrine, he concludes, is incoherent.

The dominant metaphor of conceptual relativism, that of differing points of view, seems to betray an underlying paradox. Different points of view make sense, but only if there is a common coordinate system on which to plot them; yet the existence of a common system belies the claim of dramatic incomparability. ${ }^{13}$

This argument only reaches its intended target, however, if incommensurability in fact entails incomparability, and a careful reading of Kuhn and Feyerabend reveals that for them this was never the case. In one of Kuhn's more illuminating statements on the subject he wrote:

Most readers of my text have supposed that when I spoke of theories as incommensurable, I meant that they could not be compared. But' 'incommensurability' is a term borrowed from mathematics, and there it has no such implication. The hypotenuse of an isoceles right triangle is incommensurable with its sides, but the two can be compared to any required degree of precision. What is lacking is not comparability but a unit of length in terms of which both can be measured directly and exactly. In applying the term incommensurability' to theories, I had intended only to insist that there was no common language within which both could be fully expressed and which could therefore be used in a point-by-point comparison between them. i"

Feyerabend concurs, having more recently remarked with characteristic bluntness that:

What we 'discovered' and tried to show was that scientific discourse which contains detailed and highly sophisticated discussions concerning the 
comparative advantages of paradigms obeys laws and standards that have only little to do with the naive models philosophers of science have designed for the purpose. There is comparison, even 'objective' comparison--but it is a much more complex and delicate procedure than is assumed by rationalists. ${ }^{15}$

In other words, the equation of incommensurability and incomparability rests on a confusion of two distinct notions: absence of comparability and absence of an algorithm for comparison. Kuhn has more recently introduced the notion of local incommensurability which he explicates as follows:

The claim that two theories are incommensurable is then the claim that there is no language, neutral or otherwise, into which both theories, conceived as sets of sentences, can be translated without residue or loss. No more in its metaphorical than its ifteral form does incommensurability imply incomparability, and for much the same reason. Most of the terms common to the two theories function.in the same way in both; their meanings, whatever those may be, are preserved; their translation is simply homophonic. Only for a small subgroup of (usually interdefined) terms and for sentences containing them do problems of translatability arise. The claim that two theories are incommensurable is more modest than many of its critics have supposed. 16

This means that the existence of common elements between theories is not an objection to incommensurability; rather, the incommensurable network of concepts is localized to a few, albeit important, terms: there is much that remained common to the Aristotelians and those trying to develop a dynamics to make physical sense of the new astronomy, certainly enough to make communication between their respective proponents possible. Davidson's equation of conceptual contrast with complete and mutual untranslatability is therefore incorrect; his fears of conceptual relativism, unfounded. Rorty, who as I already noted supports a version of the claim that incommensurable pairs of vocabularies or forms of discourse at least exist, points this out as well.17 He endorses the following:

By "commensurable" I mean able to be brought under a set of rules which will tell us how rational agreement can be reached on what would settle the issue on every point where statements seem to conflict. ${ }^{20}$ 
Conversely, "incommensurability" must mean an inability to arrive at such rules. This differs from the more familiar semantic thesis developed by Kuhn and Eeyerabend, just discussed. The two overlap in that semantic incommensurability can have as a consequence an absence of commensuration in Rorty's rough methodological sense. ${ }^{\prime 9}$ Rorty goes on to argue that epistemology (by which he means epistemology traditionally conceived of as a search for intellectual foundations) presupposes the possibility of ultimate commensuration between all forms of discourse. Arguments that all forms of discourse either can or should be brought into ultimate commensurability are inadequate; consequently, epistemology and all its problems ought to be set aside. Included under what ought to be set aside is the idea of a conceptual framework as a representation of the world.

Now to my mind the notion of incommensurability, even in the more modest form described above, fails to make sense unless we have some notion of alternative conceptual frameworks; otherwise there are no entities to predicate incommensurability of. Hence it now becomes necessary to show in greater detail how alternative conceptual frameworks as I conceive of them differ from what Rorty and Davidson wish to do away with, and how they can be described without resurrecting the entire Cartesian-Kantian baggage I have agreed must be jettisoned.

There are two distinct claims involved in the idea of conceptual frameworks I wish to defend. The first and deepest claim is to be found not in Kuhn-Feyerabend historicism but rather in contemporary neurophysiological research. Rorty, in a remark quoted at the outset, referred to "properly programmed organisms" as not needing an "intermediary" such as a Lockean veil of ideas. Strictly speaking, this is entirely correct, but it also loads the dice, for shouldn't we ask, What is proper programming? I argue that it consists in a complex neurophysiological apparatus, and it is this "programming" itself which provides our access to the world.

The results of contemporary neurophysiological research can hardly be adequately summarized in a paper of this size, and traditional epistemologists are liable to dismiss them as irrelevant to philosophical concerns. Their relevance to a naturalized epistemology in Quine's sense, however, should be clear. 20 The neurosciences lend unambiguous support to a distinction between the world qua physical environment and the world qua experience as a unity ordered via the natural functions of our senses and the complex which sorts through the surface irritations (as quine came to call them), retaining the relevant and filtering out the irrelevant. This level of activity has to do with the structure of the complex consisting of the brain, cen- 
tral nervous system, and senses. The structure is a result of millions of years of evolutionary adaptation to an environment, and places constraints on the range of possible "worlds" a species can experience. Neurophysiologist Harry Jerison has written:

The world as we know it ourselves represents the human grade of biological intelligence. Different worlds are presumably constructed by different species.

- The real world we know intuitively is a creation of the nervous system, a model of a possible world which enables the nervous system to handle the enormous amount of information it receives and processes. The 'true' or 'real world' is specific to a species and is dependent on how the brain of that species works. This is as true for our own world--the world as we know it--as it is for the world of any species. 21

Experiments with laboratory animals seem to bear out the claim that other species experience the physical environment differently than we do. Consider frogs. A frog's visual apparatus appears designed to respond to rapidly moving objects such as insects, but not to stationary ones. Experimenters at Harvard discovered that a captive frog will survive if kept supplied with live insects but starve if the insects are first killed: it will. starve even if surrounded by dead insects which it seems unable to sense. ${ }^{2}$ Contemporary scientific research, then, sheds new light on philosopher Thomas Nagel's musings over the problems involved in imagining "what it is like to be a bat," given the equivalent differences between the sensory apparatuses of bats and humans (although it is far from clear that Nagel's insistance on the irreducibility of the pour-soi gives him an argument against physicalism).23

This may sound suspiciously like a Kantian position so far; indeed, the physical environment as I explicated it sounds like Kant's noumenon while the world the senses construct sounds like Kant's phenomenon, with neurophysiological apparatus substituted for the more familiar Kantian categories and intuitions. I believe the analogy breaks down under close inspection; for the physical environment, unlike Kant's noumenon, is not inaccessible to us--quite the contrary, we are always in contact with aspects of it, these again being the sources of all our sensory stimuli. Different animal species are always in contact with different aspects of the physical environment, in different degrees. To say that we have merely "naturalized Kant" is therefore too easy a criticism.

The argument so far supports a kind of biological relativity, about the way different species will per- 
ceive the environment, but nothing said so far gets us from this point to an account of incommensurability and alternative conceptual frameworks within the human sphere. To accomplish this we must develop a second claim concerning a further level of activity which gives humans particular historical conceptual frameworks, namely language, which is constituted of both syntactic and semantic elements. For Noam Chomsky in particular, the human capacity to acquire and use language is biologically innate. ${ }^{24}$ Chomsky goes further and argues for the existence of a universal grammar the rules of which are also biologically innate and essential to all human languages. An assessment of this particular claim would take us far beyond the scope of the present paper; yet I sense that it can be interpreted as not conflicting with the possibility of incommensurable vocabularies. This interpretation simply follows the conventional distinction between syntax and semantics. Thus even if Chomsky is right about there being a generative grammar this doesn't affect the arguments concerning incommensurability. Unless we go much further than Chomsky and postulate a universal semantics, the most we can say is the following: The capacity to learn and use language as a precondition of thought may be biologically inborn, but the semantic apparatus attached to a given language is not, so this apparatus becomes entirely a product of one's culture or special language community, and the possibility of conceptual discontinuities between languages is left open.

The foregoing arguments should clear the way for a return to the material introduced by Kuhn, Feyerabend, Whorf, and others; this material seems to indicate that without the notion of alternative language frameworks we are simply unable to make sense of the history of science and the findings of cultural anthropologists. It is worth reiterating an additional time that much more has been read into this thesis than is really warranted. Contrary to Achinstein, Shapere, Kordig, Davidson, and others, it is simply not the case that alternative conceptual frameworks have no elements in common. Rather, they are like overlapping sets whose admittedly most crucial members, comprising what for lack of a better term I will call the "metaphysical core $^{n}$ of the language, are not shared. That the most crucial and controversial members are not shared is, of course, what makes comparison of incommensurable vocabularies difficult and requires such human traits as patience and good faith on the part of the respective proponents trying to communicate across the incommensurable divide. Such communication is almost inevitably the result of interpretation, a notion Kuhn has recently offered as an advance over quinean radical translation, explicating his view of the matter as follows: 
Quine's "radical translator" is in fact an interpreter, and 'Gavagai' exemplifies the unintelligible material he starts from. Observing behavior and the circumstances surrounding the production of the text, and assuming throughout that good sense can be made of apparently linguistic behavior, the interpreter seeks that sense, strives to invent hypotheses, like 'Gavagai' means "Lo, a rabbit," which make the utterance or inscription intelligible. If the interpreter succeeds, what he or she has in the first instance done is learn a new language, perhaps the language in which 'gagaval' is a term, or perhaps an earlier version of the interpreter's own language, one in which still current terms like 'force' and 'mass' or 'element' and 'compound' functioned different$1 y .28$

Cases of incommensurability obtain in cases where translatability fails, for, as Kuhn adds:

There need be no English description coreferential with the native term 'gavagai'. In learning to recognize gavagais, the interpreter may have learned to recognize distinguishing features unknown to English speakers and for which English supplies no descriptive terminology . . . . Under those circumstances, 'gavagai remains an irreducibly native term, not translatable into Eng11sh. Though English speakers may learn to use the term, they speak the native language when they do so. Those are the circumstances for which I would reserve the term incommensurability'.26

The difficulty we have all along had in making sense of claims such as these arises, I suggest, not from the claims themselves but out of certain assumptions built into much of both past and contemporary philosophizing, assumptions which Rorty unearths and criticizes under the name foundationalism and which Bernstein has more recently discussed as symptomatic of a "Cartesian Anxiety": either we uncover intellectual foundations for knowledge and ultimate commensuration for all vocabularies or we are faced with intellectual anarchy. 27 In my view, Rorty is right to hold that all attempts at discovering or erecting foundations, whether for knowledge. or morals, have failed and that the whole project should be abandoned. Where we part company is with Rorty's additional claim that epistemology itself is, in effect, also abandoned when we abandon foundationalism. To be sure, a certain conception of the aims of epistemology that has been very prominent this century must be given up if Rorty's arguments are sound. This is the Reichenbachian conception of epistemology as 
"concerned with constructing the context of justification" held by empiricists who have wanted to put science on a foundation of neutral sense experience." But why must we conceive of epistemology as necessarily foundational? Why, indeed, for there is an alternative conception of epistemology readily available, that being the naturalism inaugurated by Quine in particular. Rorty has hesitated, commenting that "if philosophy becomes. too naturalistic, hard-nosed positive disciplines will nudge it aside. . "2" Yes and no. Yes, in the sense that, as Quine pointed out almost two decades ago, once we naturalize epistemology there is no longer a "first philosophy" standing apart from natural science. No, in the sense that many of the issues traditional epistemologists have grappled with have not gone away and can be examined anew as scientific problems, or at the very least, as close cousins to scientific problems. To carry out a program such as this, naturalized epistemologists must be willing and able to acquire the technical conceptual machinery of such sciences as neurophysiology, putting this machinery to use in arriving at clearer and better formulations of the problems and making them more amenable to scientific attack (as opposed to so-called linguistic dissolutions). This, it seems to me, is a much more ambitious and challenging view of the epistemological enterprise than that which existed before quine, and it is more precise than Rorty's claims for the philosophy of the future as a "voice in the conversation of mankind."

To summarize the main arguments of the present paper: Rorty and Davidson have tried to dismantle the notions of conceptual frameworks and alternative conceptual frameworks. I have responded that the "scheme concept" is required to make sense of the history of science. It seems to be a necessary condition for the existence of incommensurable physical theories. The existence of alternative ways of experiencing the physical environment is supported by neurophysiological research. Even if the syntactic properties of language have a physical basis the semantic ones do not, and this opens the way for genuinely alternative ways of describing the human world. Both are relevant to a naturalized epistemology freed of the need for foundations but still closely connected with the idea of alternative conceptual frameworks.

\section{NOTES}

${ }^{2}$ Richard Rorty, "The World Well Lost," Journal of Philosophy 69 (1972): 649-65; Donald Davidson, "On the 
Very Idea of a Conceptual Scheme," Proceedings and Addresses of the American Philosophical Association $\frac{47}{47}$ (1974): 5-20; see also Richard Rorty, Philosophy and the Mirror of Nature (Princeton: Princeton University Press, 1979).

${ }^{2}$ Rorty, "The World Well Lost," 651.

"Rorty, "The World Well Lost," 650.

"Davidson, 11.

'For some hesitations over Rorty's use of the term pragmatism to characterize his enterprise see James Campbell. "Rorty's Use of Dewey," Southern Journal of Philosophy 22 (1984): 175-87.

'Norwood Russell Hanson, Patterns of Discovery (Cambridge: Cambridge University Press, 1957), 19.

TThomas S. Kuhn, The Structure of Scientific Revolutions; 2nd ed. (Chicago: University of Chicago Press, 1970), 4.

"See for example Paul Feyerabend, "Explanation, Reduction and Empiricism," Minnesota Studies in the Philosophy of Science, Vol. III (Minneapolis: University of Minnesota Press, 1962), 28-97; and Stephen Toulmin, Foresight and Understanding (Bloomington: Indiana University Press, 1961).

'I argue this point in detail in my "Incommensurability." Ph.D. dissertation, University of Georgia, in progress.

"Thomas S. Kuhn, "Commensurability, Comparability, Communicability," PSA 1982 (Ann Arbor, Mich.: Philosophy of Science Association, 1983), 669.

1 See Benjamin Lee Whorf, "An American Indian Model of the Universe," Language, Thought and Reality (Cambridge: The MIT Press. 1956), 57-64. ical discussion of Whorf's ideas in my "Incommensurability," ch. 3 .

${ }^{12}$ See for example Dudley shapere, rev. of The Structure of Scientific Revolutions, Philosophical Review 63 (1964): 383-94; Dudley Shapere, "Meaning and Scientific Change," Mind and Cosmos, ed. Robert G. Colodny (Pittsburgh: University of Pittsburgh Press. 1966), 41-85; Peter Achinstein, Concepts of Science (Baltimore: The John Hopkins Press, 1967), esp. 91-105; Carl R. Kordig, The Justification of Scientific Change (Dordrecht: D. Reidel, 1971). 
${ }^{13}$ Davidson, 6 :

"Thomas S. Kuhn, "Theory Change as Structure Change: Comments on the Sneed Formalism," Erkenntnis 10 (1976): 190-91.

${ }^{15}$ Paul Eeyerabend, "More Clothes from the Emperor's Bargain Basement," rev. of Progress and Its Problems, by Larry Laudan, British Journal for the Philosophy of Science 32 (1981): 63 .

${ }^{16}$ Kuhn, "Commensurability," 670-71.

${ }^{17}$ Rorty, Philosophy and the Mirror of Nature, 302n.

"Rorty, Philosophy and the Mirror of Nature, 316 .

19 For a brief but clear discussion of the differences between semantic and methodological incommensurability see Scott $A$. Kleiner, "Recent Theories of Theoretical Meaning," Philosophica 18 (1976): 55n. I have developed these further, adding perceptual as a third form of local incommensurability in my "Incommensurability," chs. 1 and 4 .

2 See Willard Van Orman Quine, "Epistemology Naturalized," Ontological Relativity and other Essays (New York: Columbia University Press, 1969), 69-90.

2"Harry J. Jerison, "Evolution of the Brain," The Human Brain, eds. M. C. Wittrock et al. (Englewood Cliffs, NJ: Prentice-Hall, 1977), quoted in Richard $M$. Restak, The Brain (New York: Doubleday, 1979), 87.

$22 \mathrm{~J}$. Y. Lettvin et al.. "What the Frog's Eye Tells the Erog's Brain," Proceedings of the Institute of Radio Engineers 47 (1959): 1940-51.

2"Thomas Nagel, "What Is It Like To Be a Bat?" Philosophical Review 83 (1974): 435-50.

2 "See Noam Chomsky, Language and Mind (New York: Harcourt Brace Jovanovich, 1972); and Reflections on Language (New York: Pantheon Books, 1975).

${ }^{25} \mathrm{Kuhn}$, "Commensurability," 672-73.

26 Kuhn, "Commensurability," 673.

${ }^{2}$ 'See Richard J. Bernstein, Beyond Objectivism and Relativism (Philadelphia: University of Pennsylvania Press, 1983).

2 Hans Reichenbach, Experience and Prediction (Chicago: University of Chicago Press, 1938), 7 . 
${ }^{29}$ Rorty, Philosophy and The Mirror of Nature, 168. 